\title{
Effective interfacially polymerized polyester solvent resistant nanofiltration membrane from bioderived materials
}

\author{
Mohamed H. Abdellah ${ }^{b, \dagger}$, Liliana Pérez-Manríquez ${ }^{a, \dagger}$, Tiara Puspasari ${ }^{a}$, Colin A. Scholes ${ }^{b}$, Sandra E. \\ Kentish ${ }^{\mathrm{b}}$, Klaus-Viktor Peinemann ${ }^{\mathrm{a}^{*}}$
}

Abstract: Utilization of sustainable and environmentally friendly solvents for the preparation of membranes has attracted growing interest in recent years. In this work, a polyester thin film composite solvent resistant nanofiltration (SRNF) membrane was prepared by interfacial polymerization on a cellulose support. The cellulose support was prepared by non-solvent induced phase separation from a dope solution containing an ionic liquid as an environmentally friendly solvent (negligible vapour pressure). The polyester film was formed via the interfacial reaction between quercetin, a plant-derived polyphenol, and terephthaloyl chloride. Alpha-pinene was used as a green alternative solvent to dissolve TPC while quercetin was dissolved in a $0.2 \mathrm{M} \mathrm{NaOH}$ solution. The interfacial polymerization reaction was successfully confirmed by Fourier Transform Infrared and X-Ray Photoelectron Spectroscopy while scanning electron and atomic fore microscopy were used to characterize the membrane structure. The composite membrane showed an outstanding performance with a molecular weight cut-off around 330 combined with a dimethylformamide (DMF) permeance up to $2.8 \mathrm{~L} . \mathrm{m}^{-2} \mathrm{bar}^{-1} \mathrm{hr}^{-1}$. The membrane was stable in strong aprotic solvents such as DMF offering potential application in the pharmaceutical and petrochemical industries.

\section{Introduction}

Solvent resistant nanofiltration (SRNF) is a versatile

[a] Liliana Pérez-Manríquez, Tiara Puspasari, Prof. Klaus-Viktor Peinemann

Advanced Membranes and Porous Materials Centre

King Abdullah University of Science and Technology (KAUST)

23955-6900 Thuwal, Saudi Arabia

klausviktor.peinemann@kaust.edu.sa

[b] Mohamed H. Abdellah, Dr. Colin A. Scholes, Prof. Sandra Kentish

Department of Chemical Engineering

The University of Melbourne

Parkville 3010, Melbourne, Australia

${ }^{\dagger}$ both authors contributed equally technology that has received considerable attention in recent years. This technology represents a promising alternative to conventional separation techniques such as distillation, evaporation and liquid-liquid extraction ${ }^{[1,2]}$. Compared with these technologies, SRNF is characterized by a low energy consumption as the separation occurs without phase transition ${ }^{[3]}$. Further, it operates at mild temperature preserving the heatsensitive components that are found in the pharmaceutical and food industries ${ }^{[4]}$. Many industrial applications of SRNF such as the recovery of vegetable oil, homogeneous catalysts and active pharmaceutical ingredients have been reported in the literature ${ }^{[5-12]}$. In spite of the clear advantages of SRNF, its widespread application at an industrial scale is still limited. The strong swelling and limited stability of most polymeric SRNF membranes represent the main barrier for such upscaling. Over the last few years, much work has been directed to improve the membrane stability in harsh solvents mainly by the chemical crosslinking of polymer chains ${ }^{[13-16]}$.

Interfacial polymerization is one of the most widely used techniques for the preparation of SRNF composite membranes ${ }^{[1]}$. In this approach, a thin film is formed by an instantaneous condensation reaction between two polyfunctional monomers dissolved in two immiscible solvents, one of which is typically water $^{[17]}$. Interfacial polymerization can be used for the preparation of polyamide or polyester films on the top of a porous solvent stable support ${ }^{[15,18]}$. Polyester, the focus of the present current work is produced by the reaction between an organic acid chloride dissolved in an organic solvent and a diol dissolved in water. An inorganic base is sometimes added to the aqueous phase in order to activate the diol and neutralize the by-product $\operatorname{acid}^{[17]}$. The quality and thickness of the film are 
affected by factors such as the concentration of reactants, the reaction time and the type of support ${ }^{[17]}$. Plant-derived polyphenols represent environmentally friendly monomers for the preparation of polyester films by interfacial polymerization with organic acid chloride ${ }^{[19]}$. Quercetin (Fig. 1) is a polyphenol that can be found in many plants such as caper, grapefruit, black tea, blueberries etc. ${ }^{[19,20]}$. It is characterized by a strong interfacial activity and a high crosslinking density that make it a potential alternative to harmful petrochemical-based phenols ${ }^{[19]}$. The fabrication of membranes using 'green' solvents is also an increasing focus of research. For example, Soroko et al. ${ }^{[13]}$ substituted harmful dimethylformamide (DMF) and 1,4 dioxane solvents with less toxic dimethylsulfoxide and acetone for the preparation of the polymer dope solution of crosslinked polyimide-based SRNF membranes. The authors also used water as an alternative to isopropanol in the crosslinking step.

Many materials have been used a support for the preparation of composite membranes by interfacial polymerization $^{[18,21-23]}$. However, in SRNF applications, the stability of the support material in organic solvents is very important. Cellulose is considered the most abundant renewable biopolymer on the earth ${ }^{[24]}$. It is produced from plants, trees and some living microorganisms through the condensation polymerization of glucose ${ }^{[25]}$. Cellulose has strong potential to replace hydrocarbon-based polymers as a membrane support material due to its biodegradability, chemical and thermal stability, low cost, and sustainability ${ }^{[26]}$. However, due to its limited solubility in common solvents, the utilization of cellulose for the preparation of membranes has been limited ${ }^{[27]}$. Recently, ionic liquids have shown the ability to dissolve cellulose opening a new route for the preparation of cellulose membranes via phase inversion [28-31]. Ionic liquids represent promising alternatives to volatile, toxic and flammable hydrocarbon solvents. They are in a liquid state at room temperature, consisting of a stable organic cation and an inorganic or an organic anion ${ }^{[32]}$. They are characterized by high thermal stability, nonflammability, negligible vapour pressure and low chemical reactivity ${ }^{[33]}$. Ionic liquids are considered as "green solvents" mainly because of their very low vapour pressure. There are however questions about their toxicity in waste water and their lifetime in the environment ${ }^{[8,35]}$. N-methylpyrrolidone (NMP) and dimethylacetamide (DMAc) are common solvents for polymeric membrane manufacturing. The long-term exposure to vapours of these solvents is a known risk for human health. Therefore, these solvents are listed in the Registration, Evaluation, Authorization and Restriction of Chemicals in the European Agency (REACH) and they may be banned for industrial use in the future ${ }^{[36]}$. The exposure to harmful vapours is eliminated with the use of ionic liquids as polymer solvent, but the ionic liquid ends up in the water used for membrane precipitation. This is of course the same in the case of conventional solvents. Large membrane manufacturers like hemodialyzer producer Fresenius Medical Care in Germany recover $100 \%$ of the used solvent by distillation. A recent study on sustainable wastewater treatment published in Green Chemistry concludes that adsorption technology is an even more effective technology for solvent recovery from wastewater ${ }^{[37]}$. Ionic liquids can be recovered from the aqueous precipitation bath by the same techniques. There are no quantitative data available yet, but it is very likely that the recovery of ionic liquids from wastewater is more efficient and requires less energy than the recovery of conventional solvents like DMF, DMAc and NMP. Distillation is simpler because of the negligible vapour pressure of ionic liquids. Adsorbents will be more effective and selective because of the ionic charges. Nanofiltration is an additional promising technique for ionic liquid recovery ${ }^{[38]}$. Hence, it can be concluded that the use of ionic 
liquids for membrane production eliminates the exposure of workers to harmful solvent vapours; this is the most important point. But secondly it is evident that the recovery of ionic liquids from wastewater will be more efficient than the recovery of conventional solvents.

The objective of the current work is the preparation of a polyester thin film composite membrane for SRNF applications by interfacial polymerization via an environmentally friendly route. A cellulose support membrane is prepared from a dope solution containing an ionic liquid as the solvent. For the interfacial polymerization, quercetin dissolved in $\mathrm{NaOH}$ solution is used as the aqueous phase while terephthaloyl chloride (TPC) dissolved in a-pinene acts as the organic phase. TPC is of course not a green reagent. Therefore, we kept the amount of TPC as low as possible by using a dilute solution with only $0.2 \%$ TPC. When the membrane will be produced on a continuous coating machine, the TPC solution will be applied as a liquid film not thicker than $10 \mu \mathrm{m}$ by a wick applicator or a similar device. This means, that the consumption of TPC will be below $20 \mathrm{mg}$ per square meter produced membrane. This might be tolerable taking into account that the other membrane components are bio-derived materials. $\alpha$-pinene is selected as a green substitute for harmful hydrocarbon-based solvents such as n-hexane and cyclohexane. The a-pinene is recovered form turpentine oils extracted from plants such as basil, rosemary, yarrow, parsley, and roses $^{[39]}$. Compared with typical solvents, $\alpha$-pinene has a very low flash point, a negligible vapour pressure and a high boiling point eliminating fire and explosion hazards. The resulting composite membrane is characterised by filtration of DMF as an aprotic solvent to evaluate its potential for SRNF applications<smiles>O=c1c(O)c(-c2ccc(O)c(O)c2)oc2cc(O)cc(O)c12</smiles>

Figure 1. Chemical structure of quercetin

\section{Results and Discussion}

\section{Membrane characterisation}

The proposed interfacial polymerisation reaction to form the polyester film is shown in Fig. 3 . The reactivity of the quercetin is attributed to the formation of more reactive phenoxide ions upon dissolution of the quercetin in $\mathrm{NaOH}$ solution ${ }^{[40]}$. Generally, phenols are characterized by partial acidity as they can react with strong bases resulting in the conversion of hydroxyl groups $(-\mathrm{OH})$ to phenoxide ions $\left(-\mathrm{O}^{-1}\right)^{[40,41]}$. The polyester film formation was confirmed by FTIR analysis (Fig. 2). There is no significant change in the intensity of the $\mathrm{O}-\mathrm{H}$ band in the $3000-3670$ region between the cellulose support and the composite membrane. However, compared with the cellulose support, an additional strong peak corresponding to the carbonyl group $(\mathrm{C}=\mathrm{O})$ is observed at 1730 in the composite membrane. This carbonyl group forms as a result of the reaction between quercetin and TPC (Fig. 3). The strong peak observed at 1250 in the composite membrane represents the aromatic $\mathrm{C}=\mathrm{C}$ bond that also does not exist in the cellulose support. 


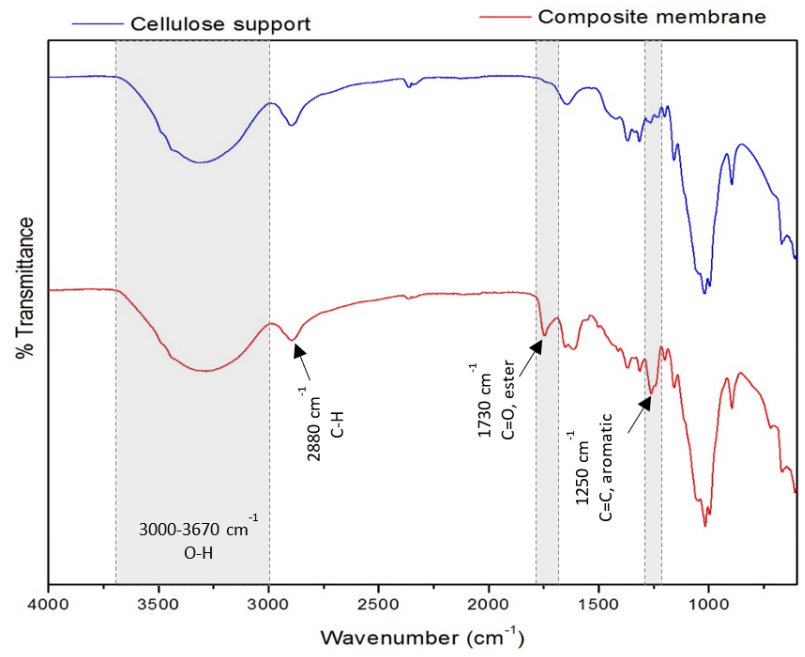

Figure 2. FTIR spectra of the cellulose support and quercetin/TPC thin-film composite membrane

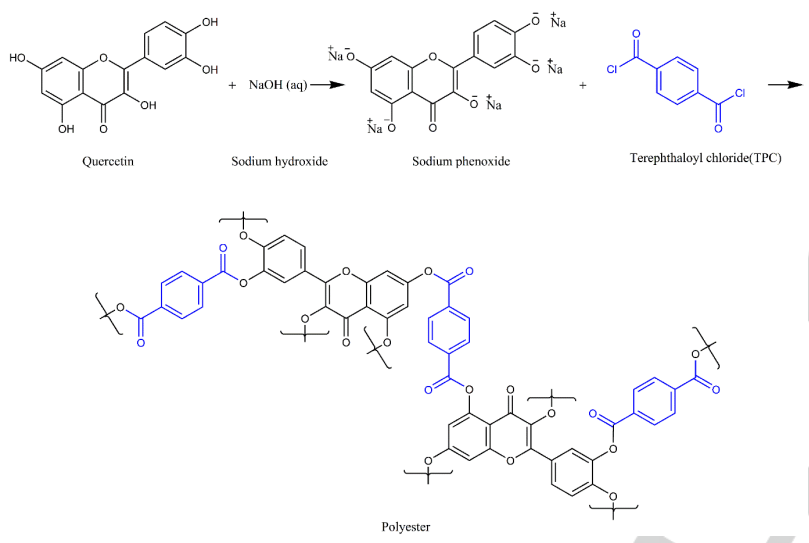

Figure 3. The reaction scheme between TPC and quercetin during interfacial polymerization

The deconvolution of the $C$ 1s core level XPS peak of the cellulose support and the composite membrane is presented in Fig. 4A and B, respectively. For the cellulose support (Fig.4A), three peaks are observed at binding energies of $284.4,286.2$ and $287 \mathrm{ev}$. These peaks correspond to the $\mathrm{C}-\mathrm{C}, \mathrm{C}-\mathrm{O}$ and $\mathrm{O}-\mathrm{C}-$ O functional groups. Unlike the cellulose support, a newly formed peak at a binding energy of 288.7 is observed for the composite membrane (Fig. 4B). This peak corresponds to the ester functional group, $\mathrm{O}=\mathrm{C}-\mathrm{O}$. The deconvolution of $\mathrm{O}$ 1s XPS peak of the cellulose support and the composite membrane is also presented in Fig. 5A and B, respectively. For both samples, the peak observed at a binding energy of 531.8 corresponds to the $\mathrm{C}-\mathrm{O}$ functional group. For the composite membrane, the new peak formed at a binding energy of $533.2 \mathrm{ev}$ corresponds to the ester functional group, $\mathrm{O}=\mathrm{C}-\mathrm{O}$. The appearance of the ester group in the composite membrane sample confirms the successful reaction between the quercetin and the TPC and the formation of the polyester film.

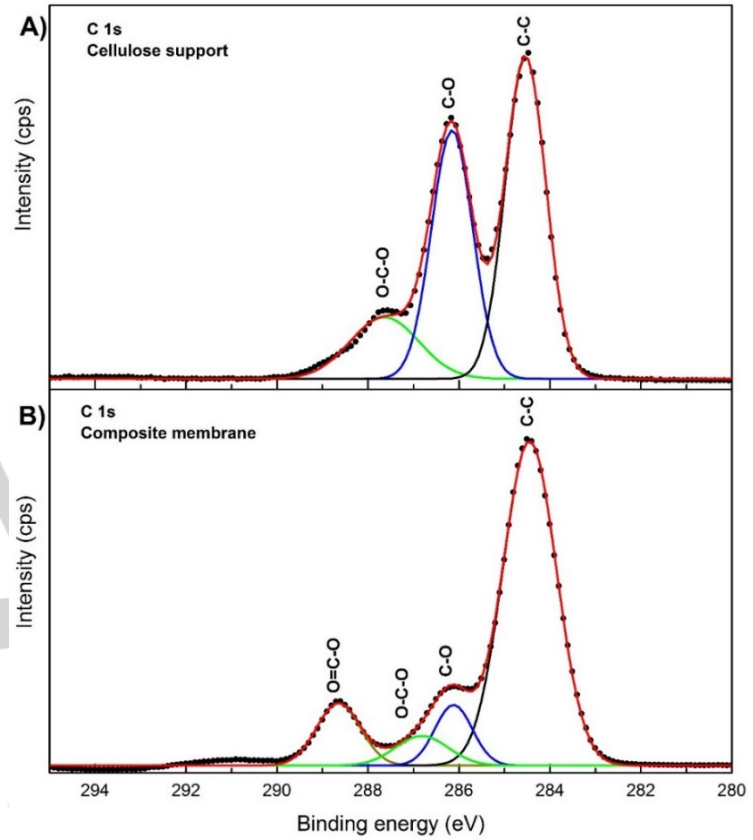

Figure 4. A high-resolution $C$ 1s core-level XPS spectrum of $A$ ) the cellulose support B) the composite membrane 


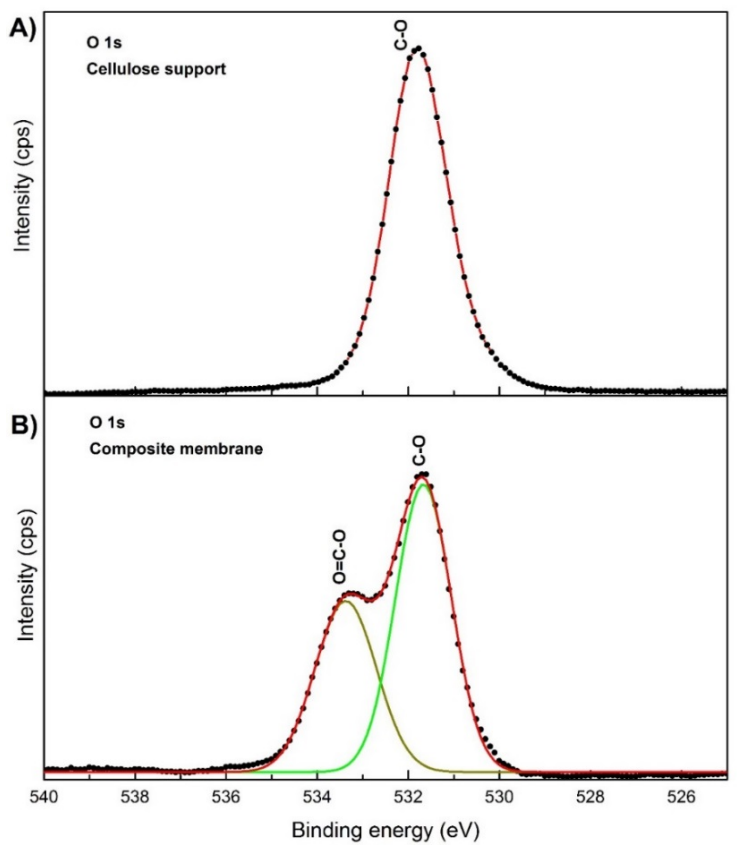

Figure 5. A high-resolution $O$ 1s core-level XPS spectrum of $A$ ) the cellulose support $B$ ) the composite membrane

Fig. $6 \mathrm{~A}$ and $\mathrm{B}$ exhibits surface and a cross-sectional images of the thin film composite membrane. A uniform thin film with no observed pores can be seen on the top of a sponge-like porous sublayer being the cellulose support.
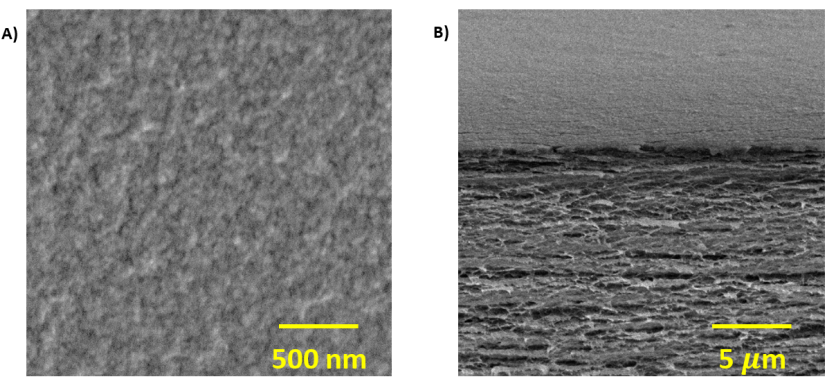

Figure 6. SEM images of the quercetin/TPC thin-film composite membrane A) surface, and B) cross-section

The surface roughness of the cellulose support and the thin film quercetin/TPC composite membrane was estimated from 2D/3D AFM images. The root-mean-square roughness $\left(R_{r m s}\right)$ was $3.5 \mathrm{~nm}$ for the cellulose support and $9.5 \mathrm{~nm}$ for the composite membrane, indicative of smooth films. There is no evidence of the 'ridge and valley' structure characteristic of classical polyamide films formed from phenylene diamine, which give root mean square roughness of $40-70 \mathrm{~nm}^{[45-47]}$. This suggests that the diffusion of quercetin into the organic phase is slow, either due to interactions of this species with the support material, or because the interfacial film that forms is impermeable to this species ${ }^{[45,46]}$

\section{Membrane performance}

The membrane performance was evaluated in terms of solvent permeance and the rejection of different molecular weight dyes (Table 1). The average pure DMF permeance through the cellulose support was $18.2 \pm 3.4 \quad$ L. m$^{-2} \mathrm{bar}^{-1} \mathrm{hr}^{-1}$, which is expected considering that cellulose membranes prepared by the NIPS method are typically porous ${ }^{[47]}$. Jimenez-Solomon et al. achieved values of 8 to 10 L. m $\mathrm{mar}^{-1} \mathrm{hr}^{-1}$ for water permeance through poly ether ketone and polyimide support structures and an acetone permeance of around 19 L. $m^{-2} b a r^{-1} h r^{-1}$ for a crosslinked polyimide support ${ }^{[46,48]}$. The permeance of pure DMF through our composite membrane was

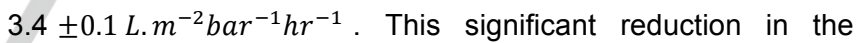
permeance is attributed to the additional mass transfer resistance introduced by the thin polyester film on the top of the porous cellulose support. The rejection of the different dyes, and the DMF permeance in the presence of these dyes is presented in Table 2. The TFC membranes prepared in this work have a MWCO of around $300 \mathrm{Da}$ (Fig. 7) and a very good DMF permeance of 2.4 to $2.8 \mathrm{~L}$. $\mathrm{m}^{-2} \mathrm{bar}^{-1} \mathrm{hr}^{-1}$, when compared with other work in literature that use a polymer support (see Table 1).

Karan et al. were able to achieve outstanding fluxes of up to 20 L. $\mathrm{m}^{-2} \mathrm{bar}^{-1} \mathrm{hr}^{-1}$ when using a sacrificial layer of cadmium hydroxide nanostrands ${ }^{[23]}$. These layers are remarkably thin $(\sim 8.4 \mathrm{~nm})$ but the approach uses chemicals that are far from environmentally friendly. 
Table 1. DMF flux and the approximate MWCO of the current work and those

Table 2. Characteristics of dyes used in the current study reported in the literature

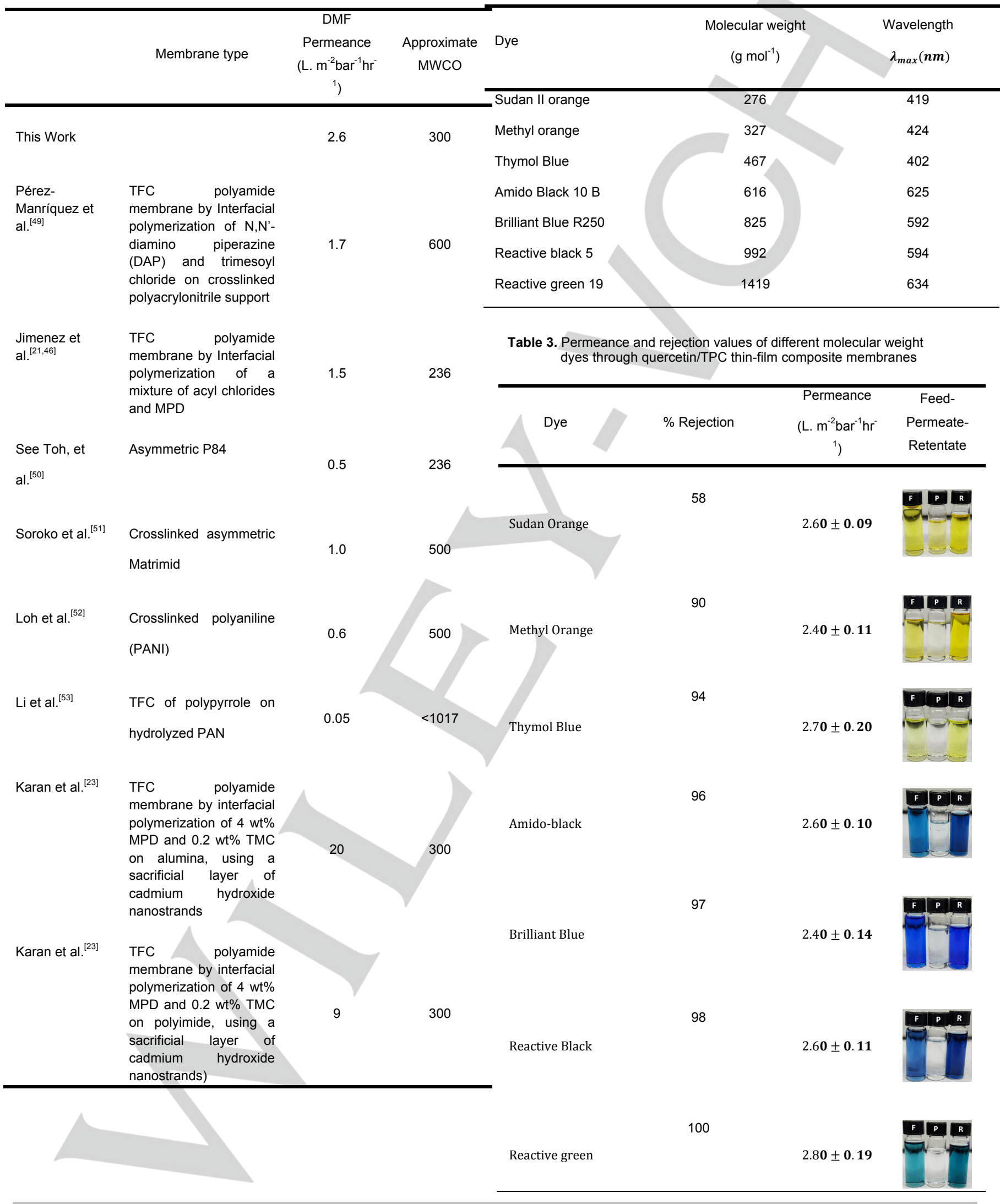




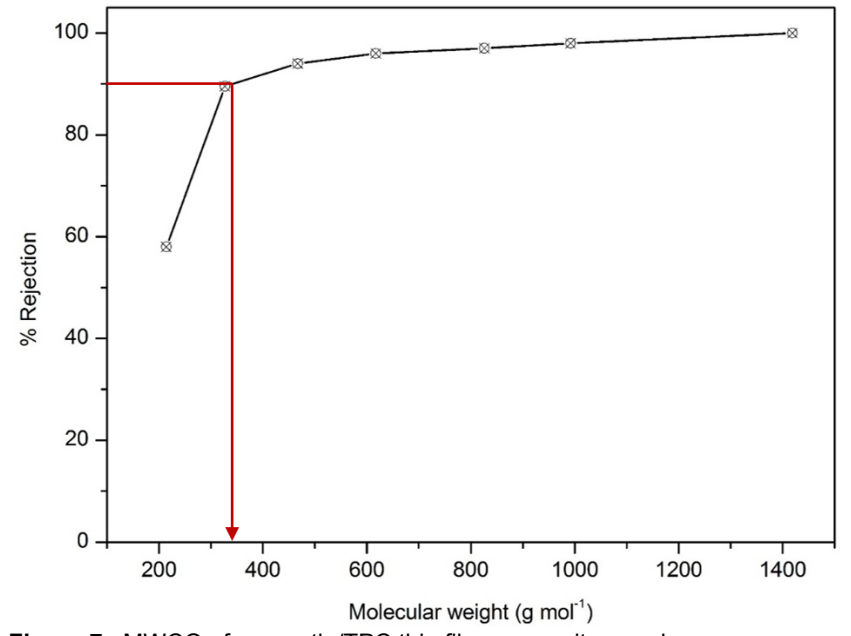

Figure 7. MWCO of quercetin/TPC thin film composite membrane

The membranes described in this work have been manufactured on small laboratory scale. Since coating by interfacial polymerization is a standard technique for industrial membrane manufacturing, the up-scaling of the manufacturing process described here should be possible.

\section{Conclusions}

A polyester/cellulose thin film composite membrane was successfully prepared by the interfacial polymerization method. An environmentally friendly ionic liquid was used to prepare the dope solution utilized for the preparation of a porous cellulose support. The green solvent $\alpha$-pinene was used as an alternative to harmful hydrocarbon solvents to dissolve the TPC monomer. As a substituent to widely-used toxic aromatic amines, naturallyoccurring quercetin was used as the second monomer for the interfacial polymerization reaction. The composite membrane showed a high stability in harsh aprotic solvents such as DMF and had a MWCO of around 300 Da (determined by different molecular weight dyes) combined with a DMF permeance of up to $2.8 \mathrm{~L} . \mathrm{m}^{-2} \mathrm{bar}^{-1} \mathrm{hr}^{-1}$. These values that are highly competitive with other polymeric systems reported in the literature. The results open the window for the utilization of sustainable, environmentally friendly materials for the preparation of SRNF membranes that are able to compete with commercially available membranes.

\section{Experimental Section}

Cellulose powder (Avicel PH101), $\alpha$ - pinene (>98 \%), N,Ndimethylformamide (DMF), quercetin, terephthaloyl chloride (TPC), 1-ethyl-3-methylimidazolium acetate (EMIM Ac, purity $97 \%$ ), sodium hydroxide pellets, Reactive Green dye, Reactive Black dye, Methyl Orange, Sudan Orange were obtained from Sigma-Aldrich. Brilliant Blue R250 and Thymol Blue (ACROS Organics $^{\mathrm{TM}}$ ) were purchased from Fisher Scientific. Amido Black 10 B was received from MP Biomedicals, France. Non-woven polyester support was purchased from Sojitz Europe, Germany.

\section{Membrane Preparation}

The cellulose support membrane was prepared by a modified non-solvent induced phase separation (NIPS) method reported in the literature ${ }^{[52,54]}$. A dope solution of $12.5 \mathrm{wt} \%$ cellulose was prepared by dissolving the cellulose powder in EMIM Ac at $80{ }^{\circ} \mathrm{C}$. The solution was stirred overnight until a homogenous solution was obtained. To minimize the potential for defect formation during membrane casting, the dope solution was degassed using an ultrasonic bath (Branson 2510) for $1 \mathrm{~h}$ prior to casting. A $250 \mu \mathrm{m}$ thick film was cast using an adjustable casting knife (BYK-Gardner) on a nonwoven polyester support. The membrane was subsequently immersed in a water coagulation bath $\left(23 \pm 1{ }^{\circ} \mathrm{C}\right)$ to complete the polymer precipitation. The membrane was kept in deionized water at ambient conditions until further use.

The polyester film was formed on the surface of the cellulose support membrane by interfacial polymerization. The wet cellulose support was fixed between a plate and frame with a 
rubber gasket using binder clips (Fig. 8A). $15 \mathrm{ml}$ of $2 \%(\mathrm{w} / \mathrm{v})$ quercetin in $0.2 \mathrm{M} \mathrm{NaOH}$ solution was poured on the top of the cellulose support within the frame (Fig. 8B). Quercetin was dissolved in $\mathrm{NaOH}$ solution due to its limited solubility in water and to enhance the interfacial polymerization reaction. The aqueous solution was maintained in contact with the cellulose support for $15 \mathrm{~min}$ ensuring the penetration of the quercetin monomer into the pores of the support. The remaining aqueous solution was then drained, and the plate-and-frame setup was disassembled. The membrane was placed on top of a filter paper and a rubber roller was gently rolled across the membrane to remove residual liquid droplets (Fig. 8C). Afterwards, the cellulose membrane was fixed again between the plate-and-frame and $15 \mathrm{ml}$ of $0.2 \%(\mathrm{w} / \mathrm{v})$ TPC/a-pinene solution was poured into the frame (Fig. 8D). After $3 \mathrm{~h}$, the excess organic solution was drained, and the membrane was washed using pure $\alpha$-pinene to remove unreacted monomers, then left to dry at ambient conditions for 10 min (Fig. 8E). Finally, the composite membrane was annealed at $50{ }^{\circ} \mathrm{C}$ for 5 min under atmospheric pressure (Fig. 8F). The resulting membranes were stored in dry conditions until use.
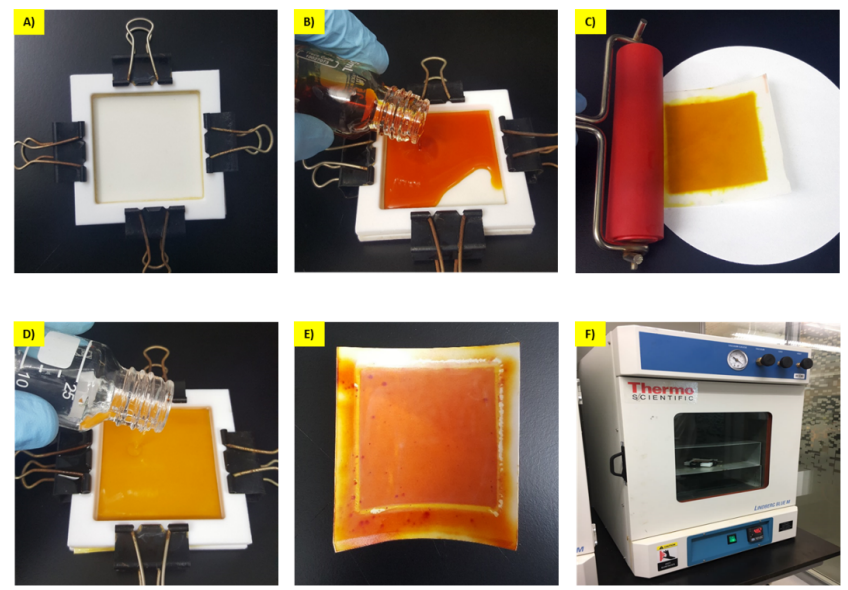

Figure 4. The protocols for the preparation of polyester TFC membranes. A) fixing the set cellulose support between the plate and frame assembly, B)

Contacting the cellulose surface with the aqueous quercetin solution $(2 \% \mathrm{w} / \mathrm{v})$ for $15 \mathrm{~min}, \mathrm{C}$ ) removal of residual aqueous solution droplets on the membrane surface using a rubber roller, D) contacting the membrane with the organic phase of $0.2 \%(\mathrm{w} / \mathrm{v}) \mathrm{TPC} / \alpha$-pinene for $3 \mathrm{hrs}, \mathrm{E})$ washing the membrane with pure $\alpha$-pinene to remove excess monomer, and F) annealing the membrane at $50{ }^{\circ} \mathrm{C}$ for $5 \mathrm{~min}$ under atmospheric pressure.

\section{Membrane characterization}

In order to confirm the successful reaction between quercetin and TPC, Fourier Transform Infrared Spectroscopy (FTIR Thermo Fisher Scientific, Model Nicolet iS10) was used. The measurement was conducted in the range of $3700-900 \mathrm{~cm}^{-1}$. Prior to analysis, the membrane samples were fully dried at $30{ }^{\circ} \mathrm{C}$ under vacuum.

X-ray Photoelectron Spectroscopy (XPS) analysis of the polyester film was carried out on a Kratos Axis Supra spectrometer equipped with a monochromatic Al Ka X-ray source $(\mathrm{hv}=1486.6 \mathrm{eV})$ operating at $150 \mathrm{~W}$, a multi-channel plate and delay line detector under a vacuum of $\sim 10-9$ mbar. All spectra were recorded using an aperture slot of $300 \mu \mathrm{m} \times 700$ $\mu \mathrm{m}$. Survey spectra were collected using a pass energy of 160 $\mathrm{eV}$ and a step size of $1 \mathrm{eV}$. A pass energy of $20 \mathrm{eV}$ and a step size of $0.1 \mathrm{eV}$ were used for the high-resolution spectra. Samples were mounted in floating mode in order to avoid differential charging. Charge neutralization was required for all samples. Binding energies were referenced to the $C$ 1s binding energy of Sp2 hybridized carbon taken to be $284.5 \mathrm{eV}$.

The membrane surface and cross-section were imaged by using a FEI Magellan XHR Scanning Electron microscope (SEM) with a voltage of $1 \mathrm{kV}$. In order to obtain sharp and welldefined cross-section images, samples were fractured in liquid nitrogen after removing the nonwoven polyester backing. The samples were then mounted on an aluminium stub and sputtered with a 2-nm thick iridium layer to avoid electrostatic charge. 
The roughness and the topography of membranes were estimated using atomic force microscopy (AFM, Agilent 5500 SPM) from images of $5 \times 5 \mu \mathrm{m}$ area. The equipment was operated under atmospheric air in acoustic AC mode.

\section{Permeation experiments}

The filtration experiments were carried out in a dead end-flow cell (STERLITECH HP4750) with a membrane active area of $12.6 \mathrm{~cm}^{2}$ (Fig. 3). All experiments were conducted at $23 \pm 1{ }^{\circ} \mathrm{C}$ and 10 bar using DMF as a solvent. The molecular weight cut-off (MWCO) was determined by measuring the rejection of different molecular weight dyes from DMF feed solutions with concentration of $35 \mu \mathrm{mol} / \mathrm{l}$. For each of the dyes, a new membrane coupon was used. Prior to filtration experiments, each of the membrane coupons was conditioned by permeating $50 \mathrm{ml}$ of pure DMF at the conditions mentioned earlier. $50 \mathrm{ml}$ of the dye solution was then loaded into the cell and $7 \mathrm{ml}$ of the permeate were collected in triplicate after discarding the first 10 $\mathrm{ml}$. The membrane permeance $(\mathrm{P})$ was calculated as follows, where $\mathrm{V}$ is the permeate volume collected $(L), \mathrm{A}$ is the active membrane area $\left(m^{2}\right), \Delta P$ is the transmembrane pressure across the membrane (bar) and $\mathrm{t}$ is the time ( $\mathrm{h}$ ).

$\mathrm{P}=\frac{\mathrm{V}}{\mathrm{A} \Delta \mathrm{Pt}} \quad \mathrm{L} \cdot \mathrm{m}^{-2} \cdot \mathrm{bar}^{-1} \cdot \mathrm{hr}^{-1}$

The rejection was calculated by measuring the dye concentration in the permeate and the retentate solutions after collecting $20 \mathrm{ml}$ of the permeate. The dye concentration was measured using a NanoDrop 2000/2000c spectrophotometer (Thermo-Fisher Scientific) adjusted to a wavelength corresponding to the maximum absorbance (Table 1). The percentage dye rejection ( $\% \mathrm{R})$ was calculated according to the following equation:

$$
\% \mathrm{R}=\frac{\mathrm{C}_{\mathrm{r}}-\mathrm{C}_{\mathrm{p}}}{\mathrm{C}_{\mathrm{r}}} \times 100
$$

Where $C_{r}$ and $C_{p}$ are the oil concentration $(\mu \mathrm{mol} / \mathrm{l})$ in the retentate and the permeate solution, respectively.

\section{Acknowledgements}

The authors gratefully acknowledge King Abdullah University of Science and Technology (KAUST) and the University of Melbourne and for their financial support.

Keywords: Quercetin • Cellulose • Interfacial polymerization • a-pinene $\bullet$ ionic liquid

[1] P. Marchetti, M. F. Jimenez Solomon, G. Szekely, A. G. Livingston Chem. Rev. 2014, 114, 10735-10806.

[2] P. Vandezande, L. E. M. Gevers, I. F. J. Vankelecom, Chem. Soc. Rev. 2008, 37, 365-405.

[3] M. Takht Ravanchi, T. Kaghazchi, A. Kargari, Desalination 2009, 235, 199-244.

[4] C. de Morais Coutinho, M. C. Chiu, R. C. Basso, A. P. B. Ribeiro, L. A. G. Gonçalves, L. A. Viotto, Food Res. Int. 2009, 42, 536-550.

[5] M. Cheryan, Membr. Technol. 2005, 2005, 5-7.

[6] X. Cao, X. Wu, T. Wu, K. Jin, B. K. Hur, Biotechnol. Bioprocess Eng. 2001, 6, 200-204

[7] J. P. Sheth, Y. Qin, K. K. Sirkar, B. C. Baltzis, J. Membr. Sci. 2003, 211, $251-261$.

[8] J. T. Scarpello, D. Nair, L. M. Freitas dos Santos, L. S. White, A. G. Livingston, J. Membr. Sci. 2002, 203, 71-85.

[9] A. P. B. Ribeiro, J. M. L. N. de Moura, L. A. G. Gonçalves, J. C. C. Petrus, L. A. Viotto, J. Membr. Sci. 2006, 282, 328-336.

[10] L. P. Rama, M. Cheryan, N. Rajagopalan, Lipid Fett 1996, 98, 10-14. [11] M. Saravanan, B. M. Bhosle, R. Subramanian, J. Food Eng. 2006, 74, $529-535$.

[12] S. S. Luthra, X. Yang, L. M. Freitas dos Santos, L. S. White, A. G. Livingston, J. Membr. Sci. 2002, 201, 65-75.

[13] I. Soroko, Y. Bhole, A. G. Livingston, Green Chem. 2011, 13, 162-168.

[14] J. Aburabie, K.-V. Peinemann, J. Membr. Sci. 2017, 523, 264-272.

[15] J. Aburabie, P. Neelakanda, M. Karunakaran, K.-V. Peinemann, React. Funct. Polym. 2015, 86, 225-232.

[16] X. Q. Cheng, Y. L. Zhang, Z. X. Wang, Z. H. Guo, Y. P. Bai, L. Shao, Adv. Polym. Technol. 2014, 33, n/a-n/a.

[17] P. W. Morgan, in Encycl. Polym. Sci. Technol., John Wiley \& Sons, Inc., 2002

[18] L. Pérez-Manríquez, P. Neelakanda, K.-V. Peinemann, J. Membr. Sci. 2017, 541, 137-142.

[19] D. G. Barrett, T. S. Sileika, P. B. Messersmith, Chem. Commun. 2014, 50, 7265-7268.

[20] Y. B. Shaik, M. L. Castellani, A. Perrella, F. Conti, V. Salini, S. Tete, B. Madhappan, J. Vecchiet, M. L. De, A. Caraffa, et al., J. Biol. Regul. Homeost. Agents 2006, 20, 47-52.

[21] M. F. Jimenez Solomon, Y. Bhole, A. G. Livingston, J. Membr. Sci. 2013, 4, 193-203.

[22] A. Zhang, R. Ma, Y. Xie, B. Xu, S. Xia, N. Gao, Desalination Water Treat. 2012, 37, 238-243.

[23] S. Karan, Z. Jiang, A. G. Livingston, Science 2015, 348, 1347-1351. [24] T. Ward, in Van Nostrands Encycl. Chem., John Wiley \& Sons, Inc., 2005.

[25] S. J. Eichhorn, Soft Matter 2011, 7, 303-315.

[26] J. Zhou, J. Chen, M. He, J. Yao, J. Appl. Polym. Sci. 2016, 133, n/a-n/a. [27] T. Heinze, U. Heinze, K. J. Edgar, Comprehensive Cellulose Chemistry, Wiley-VCH, 2009.

[28\} X.-L. Li, L.-P. Zhu, B.-K. Zhu, Y.-Y. Xu, Sep. Purif. Technol. 2011, 83, 66-73. 
[29] R. P. Swatloski, S. K. Spear, J. D. Holbrey, R. D. Rogers, J. Am. Chem. Soc. 2002, 124, 4974-4975.

[30] M. FitzPatrick, P. Champagne, M. F. Cunningham, R. A. Whitney,

Bioresour. Technol. 2010, 101, 8915-8922.

[31] F. M. Sukma, P. Z. Çulfaz-Emecen, J. Membr. Sci. 2017, DO

10.1016/j.memsci.2017.09.080.

[32] S. P. M. Ventura, F. A. e Silva, A. M. M. Gonçalves, J. L. Pereira, F.

Gonçalves, J. A. P. Coutinho, Ecotoxicol. Environ. Saf. 2014, 102, 48-54.

[33] M. Freemantle, An Introduction to lonic Liquids, 2009.

[34] Y. Zhang, B. R. Bakshi, E. S. Demessie, Environ. Sci. Techno./ 2008, 42,

$1724-1730$

[35] T.P. Thuy Pham, C.-W. Cho, Y.-S. Yun, Water Res. 2010, 44, 352-372

[36] "REACH - ECHA," can be found under

http://echa.europa.eu/regulations/reach, 2016

[37] M. Razali, J. F. Kim, M. Attfield, P. M. Budd, E. Drioli, Y. Moo Lee, G.

Szekely, Green Chem. 2015, 17, 5196-5205.

[38] J. Wang, J. Luo, X. Zhang, Y. Wan, Sep. Purif. Technol. 2016, 165, 18-

26.

[39] Z. Li, K. H. Smith, G. W. Stevens, Chin. J. Chem. Eng. 2016, 24, 215-

220

[40] T. W. G. Solomons, C. Fryhle, Organic Chemistry, John Wiley \& Sons,

2009.

[41] F. A. Carey, Organic Chemistry, McGraw-Hill, 2000

[42] P. W. Morgan, S. L. Kwolek, J. Polym. Sci. 1959, 40, 299-327.
[43] S.-Y. Kwak, S. G. Jung, Y. S. Yoon, D. W. Ihm, J. Polym. Sci. Part B Polym. Phys. 1999, 37, 1429-1440.

[44] A. Widjaya, T. Hoang, G. W. Stevens, S. E. Kentish, Sep. Purif. Technol. 2012, 89, 270-281.

[45] J. Lee, A. Hill, S. Kentish, Sep. Purif. Technol. 2013, 104, 276-283.

[46] M. F. Jimenez Solomon, Y. Bhole, A. G. Livingston, J. Membr. Sci. 2012, 423-424, 371-382.

[47] T. Puspasari, H. Yu, K.V. Peinemann, ChemSusChem 2016, 9, 2908 2911.

[48] M. F. Jimenez-Solomon, P. Gorgojo, M. Munoz-lbanez, A. G.

Livingston, J. Membr. Sci. 2013, 448, 102-113.

[49] L. Pérez-Manríquez, A. R. Behzad, K.-V. Peinemann, Macromol. Mater Eng. 2016, 301, 1437-1442.

[50] Y. H. See-Toh, M. Silva, A. Livingston, J. Membr. Sci. 2008, 324, 220-

232.

[51] I. Soroko, M. Sairam, A. G. Livingston, J. Membr. Sci. 2011, 381, 172182.

[52] X. X. Loh, M. Sairam, A. Bismarck, J. H. G. Steinke, A. G. Livingston, K Li, J. Membr. Sci. 2009, 326, 635-642.

[53] X. Li, P. Vandezande, I. F. J. Vankelecom, J. Membr. Sci. 2008, 320, 143-150.

[54] S. Livazovic, Z. Li, A. R. Behzad, K.-V. Peinemann, S. P. Nunes, J. Membr. Sci. 2015, 490, 282-293. 


\section{FULL PAPER}

A "green" membrane consisting mainly of cellulose and a natural polyphenol coating is introduced. The membrane shows excellent performance for organic solvent nanofiltration.

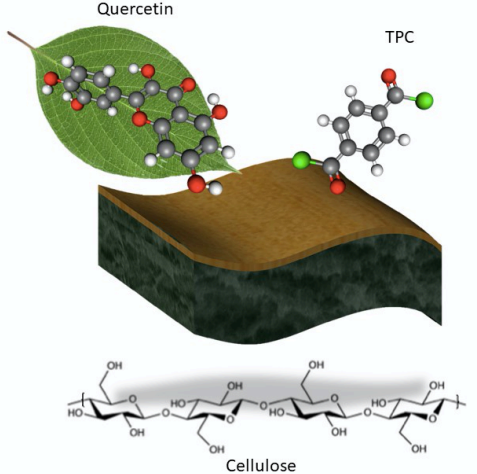

Mohamed H. Abdellah, Liliana PérezManríquez, Tiara Puspasari, Colin A. Scholes, Sandra E. Kentish, KlausViktor Peinemann

Page No. - Page No.

Effective interfacially polymerized polyester solvent resistant nanofiltration membrane from bioderived materials 